\title{
Application of thromboelastography to evaluate the effect of different routes administration of tranexamic acid on coagulation function in total hip arthroplasty
}

Xingming $\mathrm{Xu}^{1,2}$, Jiang Jiang ${ }^{2}$, Wei $\mathrm{Liu}^{1,2}$, Xiaofeng $\mathrm{Li}^{2+}$ and Huading $\mathrm{Lu}^{1 *+}$

\begin{abstract}
Background: Tranexamic acid (TXA) is widely used to reduce blood loss and transfusion rates in total hip arthroplasty(THA). Thromboelastography, which can monitor coagulation changes from clotting to fibrinolysis dynamically. In this study, thromboelastography was used to assess the dynamic changes in the coagulation of patients who underwent THA with the administration of TXA.
\end{abstract}

Methods: This randomized controlled trial consisted of 207 consecutive patients who underwent primary total hip arthroplasty. Patients were randomized into three groups: topical-TXA group received a topical application of TXA, IV-TXA group received an intravenous injection of TXA, and control group. Thromboelastography was performed 1 day before surgery and first, fourth, seventh days after surgery. The primary outcomes were thromboelastography parameters, the rates of deep vein thrombosis(DVT), and pulmonary embolism(PE). Secondary outcomes included perioperative blood loss, transfusion rates, and other perioperative complications.

Results: The mean calculated total blood loss in the Topical-TXA group were $832.7 \pm 279.84 \mathrm{ml}$ and $834.8 \pm 322.94$ $\mathrm{ml}$ in the IV-TXA group, which were significantly reduced $(p<0.05)$ compared with control groups at $1093.3 \pm$ $379.7 \mathrm{ml}$. There were no significant differences between topical-TXA and IV-TXA groups in total blood loss or transfusion rates. $K$ and $R$ have reached a nadir from preoperative levels to 4 th day postoperatively and then began to increase.a angle and $\mathrm{Cl}$ peaked from preoperative levels to the fourth day postoperatively and then began to decline.IV-TXA significantly $(p<0.05)$ promoted coagulation levels compared with topical-TXA and control groups in the early postoperative period. Almost no significant differences were observed between topical-TXA and control groups in thromboelastography parameters.No significant differences were observed in the incidence of thromboembolic complications and other perioperative complications.

Conclusions: The topical administration of TXA had the same hemostatic effect as intravenous injection tranexamic acid. Coagulation function peaked on 4th day postoperatively and then began to decline. IV-TXA was more enhanced coagulation functions compared with topical-TXA.

Keywords: Tranexamic acid, Total hip arthroplasty, Thromboelastography, Coagulation

\footnotetext{
* Correspondence: 491135186@qq.com

+Huading Lu and Xiaofeng Li contributed equally to this work.

'Department of Orthopaedic, The Fifth Affiliated Hospital Of Sun Yat-Sen

University, No. 52, Meihua East Road, Zhuhai 519000, Guangdong, China

Full list of author information is available at the end of the article
}

(c) The Author(s). 2019 Open Access This article is distributed under the terms of the Creative Commons Attribution 4.0 International License (http://creativecommons.org/licenses/by/4.0/), which permits unrestricted use, distribution, and reproduction in any medium, provided you give appropriate credit to the original author(s) and the source, provide a link to the Creative Commons license, and indicate if changes were made. The Creative Commons Public Domain Dedication waiver (http://creativecommons.org/publicdomain/zero/1.0/) applies to the data made available in this article, unless otherwise stated. 


\section{Background}

Total hip arthroplasty (THA) is currently recognized as an effective treatment for patients with hip joint disease. However, THA has been associated with considerable blood loss and massive transfusion requirements. Large number methods of controlling bleeding such as thromboplastic agents, topical freezing saline, deliberate hypotension and administration of fibrinolytic inhibitors as aprotinin and tranexamic acid (TXA) have been widely used [1-3].

Tranexamic acid (TXA) is an antifibrinolytic drug, which is widely used in total hip arthroplasty(THA) [4-6]. Many studies and meta-analyses have demonstrated that the administration of TXA could effectively decrease blood loss and transfusion rate in THA [7-10]. However, one of the major concerns for TXA is the potential increased risk of thrombosis, and that possibility cannot be overlooked. The ideal method of delivery and dosage remains controversial.

Although, ultrasound examinations are routinely performed from a macroscopic perspective and conventional coagulation assays are performed in patients who undergo THA have confirmed the safety of TXA, the dynamic changes in coagulation, platelets function, and fibrinolysis in patients administered tranexamic acid are not considered. Thromboelastography (TEG), as a blood clotting test, which can monitor coagulation changes from clotting to fibrinolysis dynamically, was widely used in the field of transplantation and blood vasculature operations [11-13]. TEG can simulate the whole process of coagulation and fibrinolysis in the human body environment, which is more sensitive than conventional coagulation assays in the evaluation of hypercoagulation, low coagulation, and fibrinolysis [14-16].

Thus, this study aimed to assess the dynamic changes in the coagulation of patients who undergo THA with the administration of TXA, to identify possible complications, and to provide an ideal application of TXA.

\section{Materials and methods}

This prospective randomized study was approved by the local ethics committee. Prior to starting this trial, informed consent was obtained from all of the patients.

\section{Inclusion and exclusion criteria}

Patients were diagnosed with osteoarthritis, and those who underwent unilateral primary cementless THA were prospectively enrolled in this trial between October 2016 and July 2018. The exclusion criteria included (1) if they had a history of hemorrhagic blood diseases; (2) preoperative anticoagulant treatment within 7 days of the surgery; (3) allergy to TXA, renal, or hepatic impairment; (4) patients with a known of the thrombotic disorder. All the included patients underwent 6 months follow-up postoperatively.

\section{Grouping and drug delivery}

Computerized block randomization was performed by an independent research assistant who was not involved in the study. Opaque sealed envelopes containing a number were opened after the patients arrived in the operating room. The numbers in the envelopes were created using a computer-generated randomization list. One of our researchers, who was not involved in the operation, was responsible for opening the envelopes and preparing the appropriate medication. Then, patients were allocated into three groups: (1) $2 \mathrm{~g}$ TXA in $50 \mathrm{ml}$ normal saline topical injection of TXA into articular cavity of hip after the uncemented prosthesis was installed and joint capsule closed (topical-TXA group); (2) 20 $\mathrm{mg} / \mathrm{kg}$ TXA in $100 \mathrm{ml}$ normal saline delivered by intravenous injection $5 \mathrm{~min}$ prior to skin incision (IV-TXA group); (3) and the control group. For all the groups, the same amounts of saline solution were applied at the same time points (if not IV injection or topical administration of TXA).

All the surgeries were performed under continuous lumbar epidural anesthesia. All surgeries were performed by the same surgeon and all the operations were completed using the posterolateral hip approach. The prosthesis was a cementless acetabular cup (Trilogy IT Acetabular System, Shell with Cluster Holes Porous, Zimmer, USA) and a cementless femoral stem (VerSys Hip System, Fiber Metal Taper, Zimmer, USA). A drain was placed in all groups and clamped for $2 \mathrm{~h}$. The drainage was removed $48 \mathrm{~h}$ after the operation. All the patients, surgeons, and outcome assessors were blinded to the randomization. All patients started passive and active function training after anesthesia resolution. An inflatable lower-extremity venous pump was applied on the first day after surgery until hospital discharge. Ten milligrams of rivaroxaban was given orally once daily for 35 days for venous thromboembolism prophylaxis.

\section{Blood transfusion protocol}

Patients received blood transfusions based on the following criteria: (1)patients with $\mathrm{Hb}$ levels less than $70 \mathrm{~g} / \mathrm{l}$; (2)patients with $\mathrm{Hb}$ levels more than $70 \mathrm{~g} / \mathrm{l}$ but with a poor mental state or other signs of distress such as pallor, polypnea, hypotension, palpitation, or dizziness.

\section{Outcome measures}

Demographic data were collected before the operation including age, gender, height, and weight. Body mass index(BMI) is the weight $(\mathrm{kg})$ divided by the square of height $\left(\mathrm{m}^{2}\right)$. Hematocrit (Hct), fibrinogen (FIB), prothrombin time (PT), and activated partial thromboplastin 
Table 1 Characteristics of the patients

\begin{tabular}{|c|c|c|c|c|}
\hline & Topical-TXA $(n=72)$ & IV-TXA $(n=68)$ & Control $(n=67)$ & \\
\hline & Mean \pm SD & Mean \pm SD & Mean \pm SD & $p$ value \\
\hline \multicolumn{5}{|l|}{ Demographic characteristics } \\
\hline Age (years) & $61.9 \pm 6.1$ & $62.5 \pm 6.6$ & $63.3 \pm 6.3$ & 0.407 \\
\hline Gender male/female & $34 / 38$ & $32 / 36$ & $35 / 32$ & 0.790 \\
\hline Body mass index $\left(\mathrm{kg} / \mathrm{m}^{2}\right)$ & $22.3 \pm 2.7$ & $22.0 \pm 2.3$ & $22.2 \pm 2.5$ & 0.637 \\
\hline \multicolumn{5}{|l|}{ Preoperative laboratory index } \\
\hline Prothrombin time (s) & $10.6 \pm 0.9$ & $10.6 \pm 0.7$ & $10.7 \pm 0.73$ & 0.889 \\
\hline APTT (s) & $28.8 \pm 4.2$ & $29.1 \pm 3.9$ & $29.3 \pm 3.5$ & 0.735 \\
\hline Plasma fibrinogen (g/L) & $2.9 \pm 0.5$ & $2.9 \pm 0.6$ & $2.9 \pm 0.5$ & 0.649 \\
\hline \multicolumn{5}{|l|}{ Postoperative complications } \\
\hline Number of DVT & 1 & 0 & 0 & 0.346 \\
\hline Number of PE & 0 & 1 & 0 & 0.327 \\
\hline Wound infection & 0 & 0 & 0 & 1.000 \\
\hline Wound hematoma & 0 & 1 & 1 & 0.423 \\
\hline Dislocation & 0 & 0 & 0 & 1.000 \\
\hline
\end{tabular}

APTT activated partial thromboplastin time, DVT deep vein thrombosis, $P E$ pulmonary embolism

time (APPT) were measured before and after the operation. The primary outcomes were TEG parameters, the rates of deep vein thrombosis(DVT), and pulmonary embolism (PE). Blood samples of $2 \mathrm{ml}$ were extracted from all patients who met the criteria before the operation and first, fourth, and seventh days after the operation, respectively. Blood was then examined by TEG (CFMS LEPU-8800, LEPU TECHNOLOGY, China), which produced five parameters including reaction time ( $R$ value), coagulation time ( $K$ value), alpha angle ( $\alpha$ angle), maximum amplitude (MA), and coagulation index $(\mathrm{CI}) . R$ is the time elapsed until the first evidence of a clot. $K$ is the time from the end of $R$ until the clot reaches $20 \mathrm{~mm}$ and represents the speed of clot formation. $\alpha$ angle is the angle of the curve made as $K$ is reached and offers information like that from $K$. The maximum amplitude (MA)is an indication of the maximum strength of the clot. A mathematical formula can be used to determine a coagulation index (CI) (or overall assessment of coagulability) that takes of these parameters into account [17].In TEG, hypercoagulability can be defined as $\mathrm{CI}>+3$. All patients underwent a routine ultrasound examination to screen for DVT on the fourth and seventh days after the operation. If the patients were suspected of pulmonary embolism(PE) based on clinic signs such as acute dyspnea or unexplained hypoxemia,a CT pulmonary angiography was performed to confirm the diagnosis. Signs of symptomatic DVT and pulmonary embolism (PE) were continuously monitored for 6 months by follow-up examinations.

The secondary outcomes were total volume of drainage, intraoperative blood loss, total blood loss, and other perioperative complications (including wound infection, wound hematoma, and dislocation). The staff who evaluated the results was blinded to the allocation. The blood volume of each patient was calculated according to the formula of Nadler et al. [18]. Total blood loss was calculated according to the formula of Gross [19].

\section{Statistical analysis}

All quantitative data were checked for homogeneity of variance and the statistical significance between groups

Table 2 The major outcomes of three groups

\begin{tabular}{|c|c|c|c|c|}
\hline & Topical-TXA $(n=72)$ & IV-TXA $(n=68)$ & Control $(n=67)$ & \\
\hline & Mean \pm SD & Mean \pm SD & Mean \pm SD & P-value \\
\hline Intraoperative blood loss (ml) & $166.7 \pm 42.5$ & $168.0 \pm 47.4$ & $176.7 \pm 46.2$ & 0.379 \\
\hline Total blood loss (ml) & $832.7 \pm 279.8^{*}$ & $834.8 \pm 322.9 \#$ & $1093.3 \pm 379.7$ & $<0.001$ \\
\hline Total volume of drainage (ml) & $91.5 \pm 48.0 \$^{*}$ & $294.4 \pm 149.7$ & $313.3 \pm 141.5$ & $<0.001$ \\
\hline Number of blood transfusion & $6(8.3 \%) *$ & 7(10.3\%)\# & $18(26.9 \%)$ & 0.004 \\
\hline
\end{tabular}

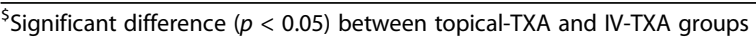

*Significant difference $(p<0.05)$ between topical-TXA and control groups

"Significant difference $(p<0.05)$ between IV-TXA and control groups 
was determined by one-way ANOVA. Pearson's chisquare test or Fisher's exact test were used to analyze the qualitative variables. The statistical analysis was performed using SPSS software (version 19.0; SPSS). A $p$ value $<0.05$ was considered significant.

\section{Results}

\section{Patients}

A total of 256 patients were screened for eligibility from October 2016 to July 2018. Thirty-four patients were excluded on the basis of our exclusion criteria, and 15 patients declined to participate. Two hundred seven patients were analyzed at last. Seventy-two patients were randomized to topical-TXA group, 68 patients were randomized to IV-TXA group, and 67 patients were randomized to the control group. The duration of postoperative follow-up in this study was 6 months. The demographic and pre-and postoperative characteristics of the patients are shown in Table 1. There were no statistically significant differences among the groups. This included no differences in baseline age, gender, body mass index, preoperative laboratory indices, or postoperative complications (deep vein thrombosis, pulmonary embolism, wound infection, and wound hematoma or dislocation).

\section{Blood loss and transfusions}

The mean total blood loss in the topical-TXA, IV-TXA, and control groups were $832.7 \pm 279.8,834.8 \pm 322.9$, and $1093.3 \pm 379.7 \mathrm{ml}$, respectively (Table 2 and Fig. 1). The topical-TXA group and IV-TXA group had significantly lower amounts of total blood loss than the control group $(p<0.05)$. There were no significant differences between topical-TXA and IV-TXA groups in total blood loss ( $p$ value $=0.970$ ). The postoperative total volume of drainage was significantly lower in the topical-TXA group than in the other two groups ( $p$ value $<0.05$ for both) (Table 2). The mean amount of intraoperative blood loss was 166.7 $\pm 42.5 \mathrm{ml}$ in the topical-TXA group, $168.0 \pm 47.4 \mathrm{ml}$ in the IV-TXA group and $176.7 \pm 46.2 \mathrm{ml}$ in the control group, with no significant intergroup differences. Six patients in the topical-TXA group, 7 patients in the IV-TXA group, and 18 patients in the control group required transfusions. These differences were statistically significant $(p$ value $=0.004)($ Table 2 and Fig. 2$)$.

\section{Thromboelastograph parameters}

There were no significant differences in $R, K, \alpha$ angle, MA, or CI among groups preoperatively (Table 3,Fig. 3, and Fig. 4). $K$ and $R$ have reached a nadir from preoperative levels to the fourth day postoperatively and then began to increase.

$\alpha$ angle and CI peaked from preoperative levels to the fourth day postoperatively and then began to decline.

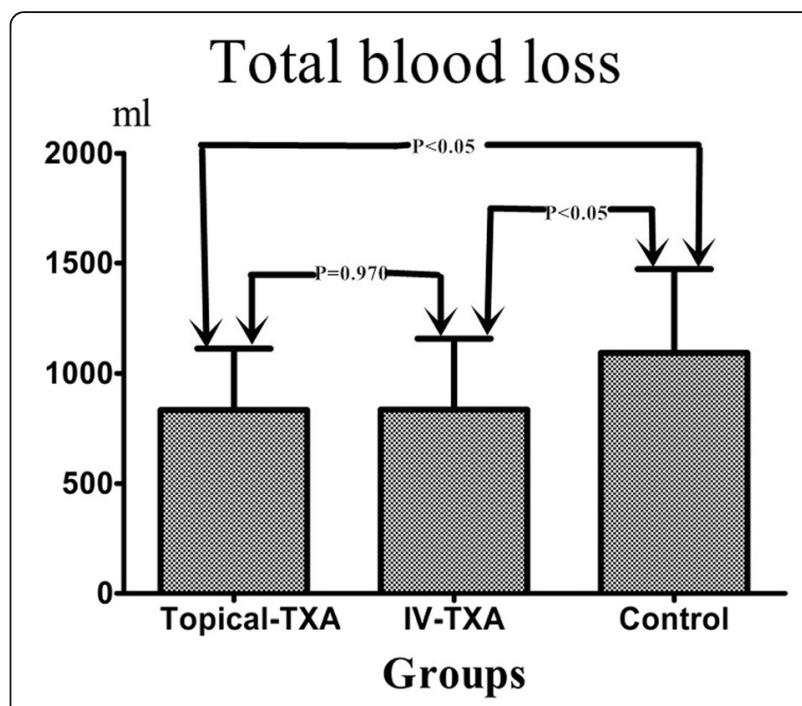

Fig. 1 The histogram demonstrated that the mean total blood loss in topical-TXA or IV-TXA group was significantly less than control groups $(P<0.05)$.There was not significant difference between IV-TXA and topical-TXA groups $(P$ value $=0.970)$

IV-TXA group enhanced coagulation peak values $(P<$ $0.05)$, but it did not obviously change the coagulation tendency in general. MA increased steadily from preoperative levels to the seventh day postoperatively.IVTXA significantly $(p<0.05)$ promoted coagulation levels in the early postoperative period (Table 3 , Fig. 3, and Fig. 4). Almost no significant differences were observed between topical-TXA and control groups (except for the $R$ on the first day postoperatively).

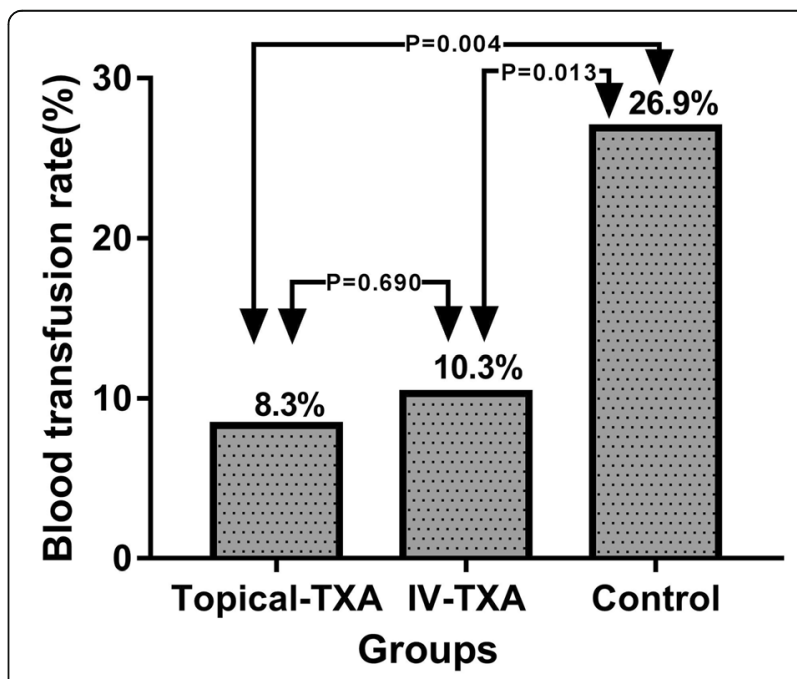

Fig. 2 The histogram demonstrated that the transfusion rates in topical-TXA or IV-TXA group was significantly less than control groups $(P=0.004$ and $P=0.013)$. There was not significant difference between IV-TXA and topical-TXA groups $(P=0.690)$ 
Table 3 Thromboelastography on preoperatively, postoperative day 1, 4, and 7

\begin{tabular}{|c|c|c|c|c|}
\hline & Topical-TXA $(n=72)$ & IV-TXA $(n=68)$ & Control $(n=67)$ & \\
\hline Items & Mean \pm SD & Mean \pm SD & Mean \pm SD & $p$ value \\
\hline \multicolumn{5}{|l|}{$R(\min )$} \\
\hline Preoperatively & $6.6 \pm 0.7$ & $6.6 \pm 0.8$ & $6.8 \pm 0.7$ & 0.247 \\
\hline \multicolumn{5}{|l|}{ Postoperative } \\
\hline Day 1 & $5.7 \pm 0.8 \$^{*}$ & $4.9 \pm 0.9 \#$ & $6.0 \pm 0.7$ & 0.000 \\
\hline Day 4 & $5.4 \pm 0.6 \$$ & $4.6 \pm 0.8 \#$ & $5.6 \pm 0.6$ & 0.000 \\
\hline Day 7 & $6.1 \pm 0.7 \$$ & $5.5 \pm 0.8 \#$ & $6.1 \pm 0.7$ & 0.000 \\
\hline \multicolumn{5}{|l|}{$K(\min )$} \\
\hline Preoperatively & $3.5 \pm 1.0$ & $3.5 \pm 0.9$ & $3.5 \pm 0.7$ & 0.904 \\
\hline \multicolumn{5}{|l|}{ Postoperative } \\
\hline Day 1 & $2.4 \pm 0.7 \$$ & $2.0 \pm 0.8 \#$ & $2.6 \pm 0.7$ & 0.000 \\
\hline Day 4 & $2.2 \pm 0.7 \$$ & $1.7 \pm 0.7 \#$ & $2.3 \pm 0.7$ & 0.000 \\
\hline Day 7 & $2.7 \pm 0.7 \$$ & $2.0 \pm 0.7 \#$ & $2.8 \pm 0.7$ & 0.000 \\
\hline \multicolumn{5}{|l|}{$\mathrm{MA}(\mathrm{mm})$} \\
\hline Preoperatively & $61.5 \pm 8.4$ & $61.3 \pm 6.9$ & $61.4 \pm 9.1$ & 0.989 \\
\hline \multicolumn{5}{|l|}{ Postoperative } \\
\hline Day 1 & $64.5 \pm 8.1$ & $66.1 \pm 6.8 \#$ & $62.1 \pm 9.2$ & 0.017 \\
\hline Day 4 & $67.4 \pm \pm 8.0 \$$ & $70.2 \pm 6.1 \#$ & $66.1 \pm 9.1$ & 0.010 \\
\hline Day 7 & $70.4 \pm 4.1$ & $70.9 \pm 4.6$ & $70.9 \pm 4.1$ & 0.695 \\
\hline \multicolumn{5}{|l|}{$a\left({ }^{\circ}\right)$} \\
\hline Preoperatively & $55.4 \pm 11.4$ & $55.2 \pm 12.3$ & $55.5 \pm 16.5$ & 0.988 \\
\hline \multicolumn{5}{|l|}{ Postoperative } \\
\hline Day 1 & $62.1 \pm 11.4$ & $66.3 \pm 12.7$ & $61.7 \pm 16.6$ & 0.092 \\
\hline Day 4 & $71.5 \pm 10.8 \$$ & $77.6 \pm 10.9 \#$ & $70.6 \pm 15.2$ & 0.002 \\
\hline Day 7 & $66.4 \pm 11.6 \$$ & $72.4 \pm 12.5 \#$ & $64.9 \pm 16.6$ & 0.004 \\
\hline \multicolumn{5}{|l|}{$\mathrm{Cl}$} \\
\hline Preoperatively & $0.4 \pm 1.0$ & $0.5 \pm 0.9$ & $0.4 \pm 0.9$ & 0.803 \\
\hline \multicolumn{5}{|l|}{ Postoperative } \\
\hline Day 1 & $1.4 \pm 1.1 \$$ & $2.0 \pm 0.8 \#$ & $1.4 \pm 0.9$ & 0.000 \\
\hline Day 4 & $2.3 \pm 1.1 \$$ & $2.9 \pm 0.9 \#$ & $2.3 \pm 0.9$ & 0.001 \\
\hline Day 7 & $1.4 \pm 1.2 \$$ & $2.0 \pm 0.8 \#$ & $1.4 \pm 0.9$ & 0.000 \\
\hline
\end{tabular}

${ }^{\$}$ Significant difference $(p<0.05)$ between topical-TXA and IV-TXA groups *Significant difference $(p<0.05)$ between topical-TXA and control groups "Significant difference $(p<0.05)$ between IV-TXA and control groups

\section{Discussion}

Tranexamic acid has been widely used in artificial hip replacement $[4-10,20]$, but there is still controversy over the method of delivery and the optimal dosage of TXA administration. The advantage of topical TXA was considered to be less systemic absorption, ease of administration, and better concentration of TXA at the bleeding site [21-23]. However, some studies have reported that topical administration of TXA can reduce blood loss and the transfusion rate but not achieve ideal satisfaction, and they hypothesized that intravenous (IV) infusion of TXA is more predictable than the topical application for reaching maximum efficacy [22, 24]. In the present study, we demonstrated that intravenous injection of tranexamic acid and topical application of tranexamic acid have the same hemostatic effect in patients undergoing primary THA, which supports a recent meta-analysis [25]. The routine dose of topical tranexamic acid is $1 \mathrm{~g}$ to $3 \mathrm{~g}$ and intravenous tranexamic acid is $10 \mathrm{mg} / \mathrm{kg}$ to 30 $\mathrm{mg} / \mathrm{kg}$ in THA $[3,25,26]$. In this study, we selected a dose of $2 \mathrm{~g}$ for topical application in the topicalTXA group and $20 \mathrm{mg} / \mathrm{kg}$ for intravenous injection in the IV-TXA group. 

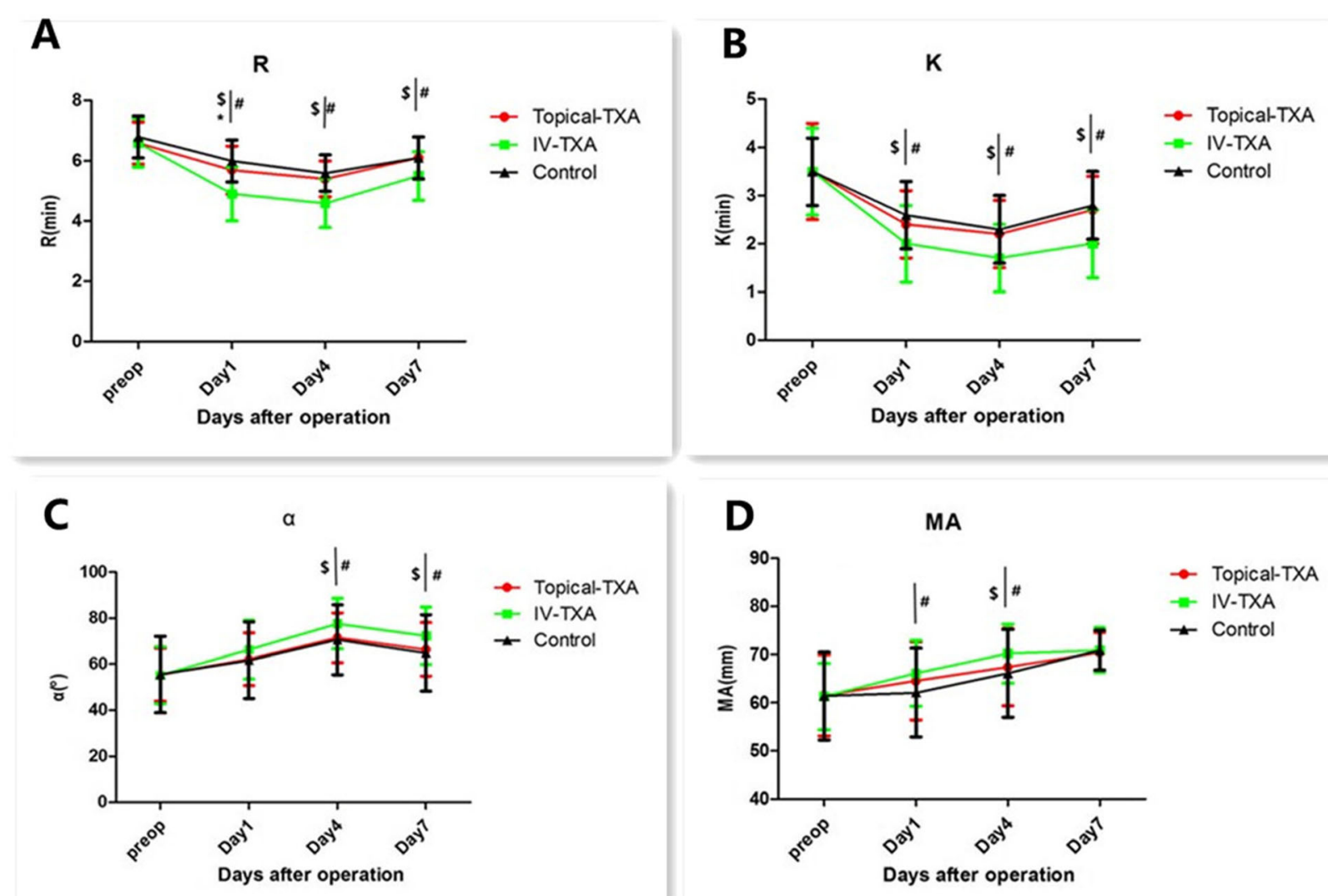

Fig. 3 Perioperative thromboelastographic parameters analysis:R time (a), $\mathrm{K}$ time (b), a angle(c), and maximum amplitude(MA) value (d). The error bars indicate standard deviation. $\$$ Significant difference $(p<0.05)$ between Topical-TXA and IV-TXA groups. *Significant difference $(p<0.05)$ between Topical-TXA and Control groups. \#Significant difference $(p<0.05)$ between IV-TXA and Control groups.Preop=preoperative

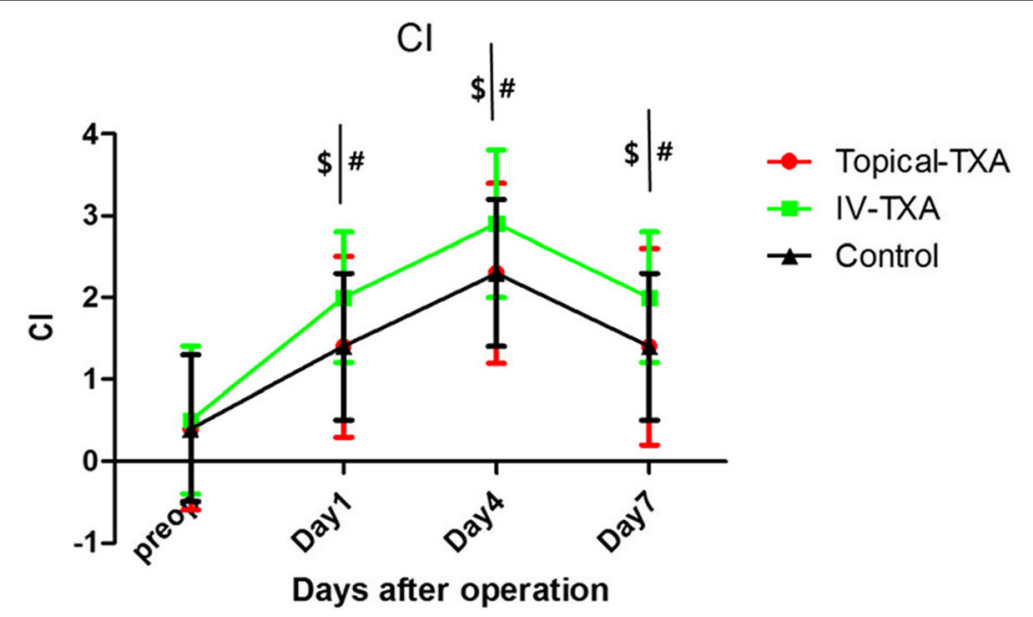

Fig. 4 Perioperative thromboelastographic $\mathrm{Cl}$ analysis.The error bars indicate standard deviation. $\$$ Significant difference $(p<0.05)$ between Topical-TXA and IV-TXA groups. ${ }^{*}$ Significant difference $(p<0.05)$ between Topical-TXA and Control groups.\#Significant difference $(p<0.05)$ between IV-TXA and Control groups.Preop=preoperative.Cl=Coagulation index 
In this study, there was one patient who developed deep vein thrombosis in the topical-TXA group, one developed pulmonary embolism in the IV-TXA group, and no patient developed a thromboembolic complication in control group. Although, there were no statistically significant differences among the groups in thromboembolic complications, the effect of tranexamic acid on the coagulation system is still unknown.

Traditional coagulation indices, including prothrombin time (PT), activated partial thromboplastin time(APTT), fibrinogen (FIB), and international normalized ratio (INR), which were widely used to monitor coagulation status. However, these traditional indices are mainly representing the initial functions of coagulation factors, which were also time-consuming. Thromboelastography [27], as a coagulation-monitoring method, which was widely used in the field of transplantation and blood vasculature operations [13, 28], monitors the dynamic process of coagulation and fibrinolysis. Zavlin et al. [14] concluded that TEG is more dynamic compared to the APTT or PT, and is exceedingly reflective of real-time coagulation status changes. While these traditional coagulation tests were not able to identify patients with thrombosis in the fields of microsurgery. Hans et al [29] also showed that TEG provides insight into the speed and strength of clot formation as well as fibrinolysis.

In this study, TEG was used to dynamically monitor coagulation from preoperation to post-operation seventh day. Thromboelastographic analysis demonstrated that coagulation function peaked on the fourth day postoperatively and then began to decline among groups. Thromboelastogram showed that intravenous injection TXA promotes hypercoagulable state (significant decrease in $R, K$, and significant increase in $\alpha$ angle, $\mathrm{CI}$ ), which was similar to what Emara et al. reported [30]. IV-TXA increased the coagulation peak values, but it did not show an obvious change in the coagulation tendency. Maximum amplitude analysis demonstrated that stronger platelet aggregation function among groups from preoperative levels to 7th day postoperation. The present study observed nearly no significant differences between topical-TXA and control groups (except for the $R$ on the first day of postoperation). That is because the topical application of tranexamic acid is less systemic absorption [31], and that has little effect on the coagulation system.

Recently, Wu et al. [32] retrospectively reviewed 359 primary total joint arthroplasty patients to evaluate the coagulation function. They concluded that multiple-dose of TXA was associated with the aggravated hypercoagulable state when compared with a single dose of TXA. Although this prothrombotic state did not provoke thrombosis, prolonged high systemic TXA levels associated with multiple injections or continuous infusion regimens may induce venous thromboembolic (VTE) events and that must be taken into consideration. In the present study, only a single dose intravenous injection with a single topical application of TXA was compared and concluded that IV-TXA was more enhanced coagulation. A prospective randomized controlled study with a large scale of patients is required in multiple-dose of the TXA field.

There were some limitations in the present study. First, the number of patients was small. Larger sample size is needed to analyze the effect of tranexamic acid on TEG parameters and to detect possible complications. Second, the postoperative TEG evaluation was performed only From the first day after surgery to the seventh day after surgery, a long postoperative dynamic monitoring is needed. Third, we do not know exactly how much TXA has permeated through articular tissue surface to the systemic circulation since serum concentrations of TXA were not measured. Fourth, asymptomatic deep vein thrombosis and pulmonary embolism were not routinely given ultrasound examination or performed routine screening during 6 months follow-up. However, we did continuously observed thromboembolic complications based on their clinical symptoms. Last, we cannot be certain whether TXA has a negative effect on the osseous integration of the implants or on joint wear.

In conclusion, the present study demonstrated that the topical administration of TXA had the same hemostatic effect as intravenous tranexamic acid on reducing perioperative total blood loss. Coagulation function peaked on the fourtth day postoperatively and then began to decline. IV-TXA was more enhanced in coagulation functions compared with topical-TXA, but it did not change the coagulation tendency.TEG is a reliable tool to understand the coagulation status of patients undergoing THA.

\section{Abbreviations \\ APPT: Activated partial thromboplastin time; Cl: Coagulation index: \\ DVT: Deep vein thrombosis; FIB: Fibrinogen; Hct: Hematocrit; \\ INR: International normalized ratio; MA: Maximum amplitude; PE: Pulmonary embolism; PT: Prothrombin time; R: Reaction time; \\ TEG: Thromboelastography; THA: Total hip arthroplasty; TXA: Tranexamic acid}

\section{Acknowledgements}

Not applicable

\section{Grant disclosures}

This research received no specific grant from any funding agency, commercial or not-for-profit sectors.

\section{Authors' contributions}

XMX participated in the design of the study, was the national coordinator of the trial, and wrote the manuscript. JJ carried out the data collection and performed the statistical analysis. WL involved in the overall supervision participated in the preparation of the questionnaire and analysis of data. LXF and HDL participated in the design of the study and validated the final results as the president of the scientific committee, and participated in the manuscript writing. All authors read, commented, made changes, and then approved the final manuscript. 


\section{Funding}

This study was supported by the National Natural Science Foundation (grant no. 81572174)

\section{Availability of data and materials}

The datasets used and/or analyzed during the current study are available from the corresponding author on reasonable request.

\section{Ethics approval and consent to participate}

The ethic approval of this study was obtained from the Institutional Ethics Committee of The First Affiliated Hospital of Nanchang University. Informed and written consent was obtained from all patients.

\section{Consent for publication}

Not applicable

\section{Competing interests}

The authors declare that they have no competing interests.

\section{Author details}

'Department of Orthopaedic, The Fifth Affiliated Hospital Of Sun Yat-Sen University, No. 52, Meihua East Road, Zhuhai 519000, Guangdong, China. ${ }^{2}$ Department of Orthopaedics, The First Affiliated Hospital Of Nanchang University, No. 17, Yongwaizheng Street, Nanchang 330006, Jiangxi, China.

\section{Received: 7 October 2019 Accepted: 27 November 2019}

\section{Published online: 11 December 2019}

\section{References}

1. Bannister GC, Young SK, Baker AS, Mackinnon JG, Magnusson PA. Control of bleeding in cemented arthroplasty. J Bone Joint Surg Br. 1990;72:444-6.

2. Verstraete M. Clinical application of inhibitors of fibrinolysis. Drugs. 1985;29: 236-61

3. Zhao Z, Ma J, Ma X. Comparative efficacy and safety of different hemostatic methods in total hip arthroplasty: a network meta-analysis.Journal of Orthopaedic Surgery and. Research. 2019;14:4. https://doi.org/10.1186/ s13018-018-1028-2

4. Xu X, Li X, Liu W, Wang Z. Longtime soaking of high concentration tranexamic acid in total hip arthroplasty: A prospective randomized controlled trial in 224 patients. Pak J Med Sci. 2015:31(6):1306-11.

5. Xu S, Chen JY, Zheng Q, Lo NN, Chia SL, Tay KJD, Pang HN, Shi L, Chan ESY, Yeo SJ. The safest and most efficacious route of tranexamic acid administration in total joint arthroplasty: A systematic review and network meta-analysis. Thromb Res. 2019;176:61-6.

6. Fillingham YA, Ramkumar DB, Jevsevar DS, Yates AJ, Shores P, Mullen K, Bini SA, Clarke HD, Schemitsch E, Johnson RL, Memtsoudis SG, Sayeed SA, Sah AP, Della Valle CJ. The efficacy of tranexamic acid in total hip arthroplasty: a network Meta-analysis. J Arthroplasty. 2018;33(10):3083-9.

7. Yoon BH, Kim TY, Ko YS, Lee YK, Ha YC, Koo KH. Optimal use of tranexamic acid for total hip arthroplasty:A network meta-analysis. PloS One. 2018; 13(10):e0206480. https://doi.org/10.1371/journal.pone.0206480.

8. Clavé A, Gérard R, Lacroix J, Baynat C, Danguy des Déserts M, Gatineau F, Mottier D. A randomized,double-blind,placebo-controlled trial on the efficacy of tranexamic acid combined with rivaroxaban thromboprophylaxis in reducing blood loss after primary cementless total hip arthroplasty. Bone Joint J. 2019;101-B(2):207-12

9. Han X, Gong G, Han N, Liu M. Efficacy and safety of oral compared with intravenous tranexamic acid in reducing blood loss after primary total knee and hip arthroplasty: a meta-analysis. BMC Musculoskelet Disord. 2018;19(1):430.

10. Wilde JM, Copp SN, McCauley JC, Bugbee WD. One dose of intravenous tranexamic acid is equivalent to two doses in total hip and knee arthroplasty. J Bone Joint Surg Am. 2018:100(13):1104-9.

11. Yoon JU, Cheon JH, Choi YJ, Byeon GJ, Ahn JH, Choi EJ, Park JY. The correlation between conventional coagulation tests and thromboelastography in each phase of liver transplantation. Clin Transplant. 2019:33(3):e13478

12. Campbell RAS, Thomson EM, Beattie C. Effect of liver disease etiology on ROTEM profiles in patients undergoing liver transplantation. Transplant Proc. 2019;51(3):783-9.
13. Bhardwaj V, Malhotra P, Hasija S, Chowdury UK, Pangasa N. Coagulopathies in cyanotic cardiac patients: an analysis with three point-of-care testing devices (Thromboelastography, rotational thromboelastometry,and sonoclot analyzer). Ann Card Anaesth. 2017;20(02):212-8.

14. Zavlin D, Chegireddy V, Jubbal KT, Agrawal NA, Spiegel AJ. Management of microsurgical patients using intraoperative unfractionated heparin and thromboelastography. J Reconstr Microsurg. 2019;35(3):198-208.

15. Franchi F, Hammad JS, Rollini F, et al. Role of thromboelastography and rapid thromboelastography to assess the pharmacodynamic effects of vitamin K antagonists. J Thromb Thrombolysis. 2015;40:118-25.

16. Bachli EB, Bösiger J, Béchir M, Stover JF, Stocker R, Maggiorini M, Renner EL, Müllhaupt B, Schuepbach RA. Thromboelastography to monitor clotting/ bleeding complications in patients treated with the molecular adsorbent recirculating system. Crit Care Res Pract. 2011;2011:1.

17. Donahue SM, Otto CM. Thromboelastography:A tool for measuring hypercoagulability,hypocoagulability,and fibrinolysis. J Vet Emerg Crit Care. 2005:15:9-16.

18. Nadler SB, Hidalgo JU, Bloch T. Prediction of blood volume in normal human adults. Surgery. 1962;51:224-32

19. Gross JB. Estimating allowable blood loss:corrected for dilution. Anesthesiology. 1983;58:277-80.

20. Wang L, Cao JG, Liu J. Comparison between oral and intravenous application of tranexamic acid for total hip arthroplasty: a meta-analysis. J Comp Eff Res. 2019:8(6):423-30.

21. Alshryda S, Mason J, Sarda P, Nargol A, Cooke N, Ahmad H, Tang S, Logishetty R, Vaghela M, McPartlin L, Hungin AP. Topical(intraarticular)tranexamic acid reduces blood loss and transfusion rates following total hip replacement:a randomized controlled trial(TRANX-H). J Bone Joint Surg Am. 2013;95(21):1969-74

22. Wind TC, Barfield WR, Moskal JT. The effect of tranexamic acid on transfusion rate in primary total hip arthroplasty. J Arthroplasty. 2014;29(2) 387-9.

23. Martin JG, Cassatt KB, Kincaid-Cinnamon KA, Westendorf DS, Garton AS, Lemke JH. Topical administration of tranexamic acid in primary total hip and total knee arthroplasty. J Arthroplasty. 2014;29(5):889-94.

24. Alshryda S, Mason J, Vaghela M, et al. Topical (intra-articular) tranexamic acid reduces blood loss and transfusion rates following total knee replacement: a randomized controlled trial (TRANX-K). J Bone Joint Surg Am. 2013;95(21):1961-8.

25. Li J, Zhang Z, Chen J. Comparison of efficacy and safety of topical versus intravenoustranexamic acid in total hip arthroplasty: A meta-analysis. Medicine(Baltimore). 2016;95(36):e4689.

26. Zhang $P$, Liang $Y$, Chen $P$, Fang $Y$, He J, Wang J. Intravenous versus topical tranexamic acid in primary total hip replacement: A meta-analysis. Medicine (Baltimore). 2016;95(50):e5573.

27. Wikkelsø A, Wetterslev J, Møller AM, Afshari A. Thromboelastography (TEG) or rotational thromboelastometry (ROTEM) to monitor haemostatic treatment in bleeding patients: a systematic review with meta-analysis and trial sequential analysis. Anaesthesia. 2017;72(4):519-31.

28. Hawkins RB, Raymond SL, Hartjes T, Efron PA, Larson SD, Andreoni KA Thomas EM. Review: The perioperative use of thromboelastography for liver transplant patients. Transplant Proc. 2018;50(10):3552-8.

29. Hans GA, Besser MW. The place of viscoelastic testing in clinical practice. $\mathrm{Br}$ J Haematol. 2016;173:37-48.

30. Emara WM, Moez KK, Elkhouly AH. Topical versus intravenous tranexamic acid as a blood conservation intervention for reduction of post-operative bleeding in hemiarthroplasty. Anesth Essays Res. 2014:8(1):48-53.

31. Wong J, Abrishami A, El Beheiry H, Mahomed NN, Roderick Davey J, Gandhi $R$, Syed KA, Muhammad Ovais Hasan S, De Silva Y, Chung F. Topical application of tranexamic acid reduces postoperative blood loss in total knee arthroplasty: a randomized,controlled trial. J Bone Joint Surg Am. 2010; 92(15):2503-13.

32. Wu XD, Chen Y, Tian M, He Y, Tao YZ, Xu W, Cheng Q, Chen C, Liu W, Huang W. Application of thrombelastography (TEG) for safety evaluation of tranexamic acid in primary total joint arthroplasty. J Orthop Surg Res. 2019; $14(1) \cdot 214$

\section{Publisher's Note}

Springer Nature remains neutral with regard to jurisdictional claims in published maps and institutional affiliations. 